\title{
Entrevista a Armin von Bogdandy
}

22 de marzo de 2021

Revista Derechos en Acción ISSN 2525-1678/ e-ISSN 2525-1686

Año 6/No 18, Verano 2020-2021 (21 diciembre a 20 marzo), 837-845

DOI: https://doi.org/10.24215/25251678e498

Armin von Bogdandy es un jurista alemán. Es director del Instituto Max Planck de Derecho Público Comparado y Derecho Internacional de Heidelberg (Alemania) y profesor de Derecho Público, Derecho Europeo y Derecho Internacional y Económico en la Universidad Goethe de Fráncfort (Alemania). Entre otros galar-

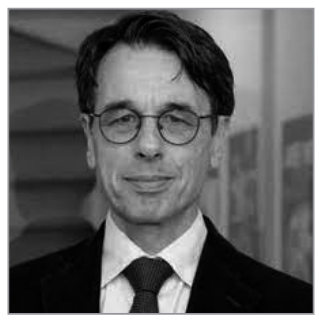
dones, recibió el premio de la Academia de Ciencias de Berlín-Brandeburgo por sus destacados logros científicos en el campo de los fundamentos jurídicos y económicos en 2008, el premio Gottfried Wilhelm Leibniz en 2014 y el "Mazo" de la Corte Interamericana de Derechos Humanos en 2015. Es presidente del Tribunal Europeo de Energía Nuclear.

- Recientemente ha publicado junto con otra/os colegas el libro El constitucionalismo transformador en América Latina y el derecho económico internacional. De la tensión al diálogo. ¿Cómo puede este abordaje contribuir a las discusiones respecto al FMI y los derechos humanos en la región?

-El constitucionalismo transformador busca provocar un profundo cambio social para que las promesas plasmadas en el texto constitucional se realicen, particularmente con relación a los principios de la democracia, el Estado de derecho y los derechos 
humanos. Si bien este fenómeno existe en diferentes partes del mundo, el constitucionalismo transformador en América Latina se distingue por estar arraigado y estrechamente entrelazado con el derecho interamericano de los derechos humanos. Por esta razón es que nos referimos a este tipo de constitucionalismo como Ius Constitutionale Commune en América Latina. Considera los desafíos específicos de la región, en especial el alto grado de exclusión social y de desigualdad económica, la inseguridad y la violencia generalizada, así como la selectiva eficacia de las instituciones y de la aplicación de la ley. La preocupación que estas problemáticas despiertan se ve acentuada por la pandemia que exacerba las ya existentes desigualdades y la marginalización socioeconómica a lo largo y ancho de la región.

La motivación para hacer este libro surgió de la observación de que los objetivos de este constitucionalismo regional podrían verse considerablemente afectados por los instrumentos del derecho económico internacional. Por ejemplo, los capítulos de propiedad intelectual en los acuerdos comerciales bilaterales pueden tener implicaciones en el derecho a la salud garantizado por muchas constituciones nacionales y tratados internacionales de derechos humanos, mientras que los acuerdos internacionales de inversión se han invocado, entre otras cosas, contra las políticas nacionales diseñadas para proteger los derechos de los pueblos indígenas. Dicho esto, las garantías previstas por las constituciones latinoamericanas, en particular aquellas ligadas a los derechos socioeconómicos, solo pueden realizarse luego de haber alcanzado un cierto nivel de desarrollo social y económico. Al fomentar ese desarrollo, el derecho económico internacional, si se diseña adecuadamente, también podría contribuir al avance del constitucionalismo transformador en la región.

Es en este contexto que interviene la publicación de nuestro libro. Éste destaca la necesidad de provocar un cambio en el diseño y la aplicación de los instrumentos del derecho económico internacional para reducir las tensiones con el constitucionalismo transformador, sobre todo en el ámbito de los derechos 
humanos. Si bien el libro no trata en profundidad sobre el FMI, sí da una serie de propuestas desde una perspectiva legal para evitar efectos adversos en los derechos humanos, y algunas de ellas son relevantes para el Fondo. Particularmente, en el capítulo en coautoría con Franz Ebert, en el que abordamos el Banco Mundial, mostramos un número de posibilidades para alinear las actividades del Banco con los objetivos y principios del constitucionalismo transformador. En particular, planteamos que, a la hora de diseñar y ejecutar sus actividades, el Banco Mundial debería considerar no sólo los estándares globales de derechos humanos sino también el acervo interamericano de derechos humanos. Para esto desarrollamos varias propuestas jurídicas sobre cómo llevarlo a cabo. Además, sostenemos que deben mejorarse los mecanismos de rendición de cuentas del Banco Mundial en materia de derechos humanos, que son esenciales para abordar los déficits de legitimidad a los que han dado lugar las actividades del Banco Mundial. Estos aspectos son también relevantes para las actividades del FMI cuyo marco legal muestra déficits en materia de derechos humanos similares a los del Banco Mundial.

-El FMI siempre argumenta que, a la hora de otorgar préstamos o de ofrecer asesoramiento técnico, no está autorizado ni obligado jurídicamente a tomar en consideración los derechos humanos. ¿Puede el derecho público internacional arrojar luz sobre este asunto?

-Existen muchas razones para considerar que tanto el FMI como otras instituciones financieras internacionales están sujetas a determinadas normas internacionales de derechos humanos. Hasta ahora, las instituciones financieras internacionales no son parte en los tratados globales o regionales de derechos humanos. Dicho esto, cabe aclarar que sí son sujetos del derecho internacional, es decir que están regidas por las normas perentorias del ius cogens y el cuerpo relevante del derecho consuetudinario internacional. 
Otra razón, quizá más convincente todavía, para considerar que el FMI está obligado a tomar en cuenta los derechos humanos a la hora de planificar y ejecutar sus actividades, radica en el mandato mismo del FMI. Matthias Goldmann, por ejemplo, afirmó de manera convincente que el mandato del FMI ha evolucionado a través de las últimas décadas de tal modo que ha incorporado la obligación de, por lo menos, no contribuir a violaciones de los derechos humanos, incluyendo los derechos económicos, sociales y culturales. De hecho, las instituciones financieras internacionales se comprometieron a cumplir con los Objetivos de Desarrollo Sostenible de las Naciones Unidas que abarcan numerosos asuntos relativos a los derechos humanos. Finalmente, es importante tener en cuenta la condición del FMI como agencia especializada de las Naciones Unidas en virtud de su acuerdo de relación con las Naciones Unidas. Puede afirmarse que esto implica que el FMI está obligado a respetar los principios y objetivos de las Naciones Unidas, de los que los derechos humanos son una parte importante como lo evidencia el Artículo 1(3) de la Carta de las Naciones Unidas.

Vale la pena señalar que la forma en la que los instrumentos legales del FMI están redactados ofrece vías significativas para tomar en consideración las inquietudes sobre derechos humanos. Por ejemplo, las Directrices del FMI sobre la Condicionalidad de 2002 requieren de éste "que tenga debidamente en cuenta los objetivos sociales y políticos nacionales" (traducción propia del inglés). Este tipo de disposiciones pueden ser interpretadas de forma tal que permita $-y$ de hecho exija- al FMI atender debidamente las consideraciones en derechos humanos en el transcurso de sus operaciones.

- ¿Es la fragmentación del derecho internacional un problema a la hora de pensar las obligaciones del FMI en materia de derechos humanos? Y si es así, ¿cómo es posible superarla?

- La naturaleza fragmentada del derecho internacional hace que los Estados puedan enfrentarse con requisitos contradictorios 
entre el derecho internacional de los derechos humanos, por un lado, y los programas de asistencia financiera del FMI, por el otro. Hemos visto en diversas ocasiones cómo la condicionalidad del FMI les exigió a algunos países tomar medidas que, según organismos internacionales de derechos humanos como el Comité de Derechos Económicos, Sociales y Culturales, o el Comité Social Europeo, eran contrarias a las pertinentes obligaciones del Estado en materia de derechos humanos.

Desde un punto de vista normativo, las razones para superar esta fragmentación son sólidas, en lo que concierne a los derechos humanos. Uno de los puntos en los que hacen hincapié los Objetivos de Desarrollo Sostenible de las Naciones Unidas, entre otros, es la necesidad de una coherencia política a nivel global. Para que ésta se materialice, es esencial que el FMI tome en consideración las inquietudes en derechos humanos de manera sistemática a la hora de diseñar sus actividades. Esto requerirá cambios en las prácticas institucionales del Fondo. Por ejemplo, los programas de asistencia financiera del FMI, incluyendo las condiciones que imponen, deberían estar acompañados de evaluaciones ex-ante sobre los impactos en los derechos humanos para poder identificar los efectos negativos y abordarlos antes de que se materialicen. En algunos casos, las evaluaciones expost servirían para rastrear los efectos de algunas actividades del FMI en materia de derechos humanos a lo largo del tiempo. Para que estas evaluaciones sean efectivas, es imprescindible una sólida metodología que incluya elementos cuantitativos y cualitativos. Además, se necesitaría un marco procedimental adecuado para garantizar la independencia de la institución que lleva a cabo la evaluación y los recursos necesarios para ello. Es importante mencionar que los programas de asistencia financiera del FMI no son los únicos en suscitar cuestionamientos en materia de derechos humanos que necesitan ser atendidos. Más bien, es posible hacer una observación similar respecto a los instrumentos del FMI para evaluar las políticas nacionales de sus países miembros, como los llamados Informes del 
Artículo IV del FMI que son preparados por el personal del FMI y muchas veces conllevan implicaciones problemáticas con relación a los derechos humanos. Como demostró Franz Ebert, estos Informes tendrían que ser considerados como el ejercicio de una autoridad pública internacional, dada la influencia que tienen en la elaboración de políticas públicas de muchos países.

Otro tema crucial a este respecto es la cuestión de la coordinación entre el FMI y otras instituciones internacionales, especialmente aquellas con mandato en derechos humanos. A nivel nacional es habitual que un miembro del gobierno cuya acción propuesta afecta el área de competencia de otro , al menos, debe informar y consultar con este último, en aras de la coherencia de las políticas.. Así también, a nivel internacional, en los casos en los que una decisión por parte de una organización internacional impacte en cuestiones que competen al mandato de otra, ésta última debería como mínimo ser informada y tener la oportunidad de brindar su opinión sobre el asunto. Esto requeriría, por ejemplo, que el FMI consulte con instituciones como la Comisión Interamericana de Derechos Humanos o la Organización Internacional del Trabajo con respecto a las reformas de la seguridad social o la legislación laboral prescritas en las condiciones de los préstamos del FMI o propuestas en los informes del artículo IV.. De este modo, el FMI no se convertiría en una agencia de aplicación de derechos humanos, sino que garantizaría que sus recomendaciones estén basadas en los conocimientos especializados pertinentes y que cuenten con la aprobación de la institución internacional competente.

-Más allá de las IFI, ¿es posible pensar en un marco legal internacional que tome en consideración de manera sustentable tanto los derechos humanos como los mercados de crédito privado?

-En mi opinión, es sumamente necesario mejorar el marco legal dentro del cual se reestructura la deuda soberana. Como jurista del derecho público me interesa cómo los ejercicios 
de autoridad pública pueden ser controlados y enmarcados para hacerlos más legítimos. En un artículo en coautoría con Matthias Goldmann, mostramos que en varios foros, dentro de los cuales se lleva a cabo la restructuración de la deuda soberana, involucran este tipo de ejercicios de autoridad pública. Esto es particularmente cierto en el caso del Club de París que está compuesto por los principales países deudores. Lo hace a través de las Minutas Acordadas ("Agreed Minutes") con las que se concluyen las negociaciones de reestructuración de la deuda soberana dentro del mismo Club de París. Si bien no son formalmente vinculantes, las Minutas Acordadas fijan las expectativas normativas de los actores involucrados y pueden ser implementadas a través de las acciones unilaterales de sus miembros contra países deudores.

En nuestro artículo sostenemos que estos ejercicios de autoridad pública suscitan problemas de legitimidad que deberían ser abordados a través de un fortalecimiento de los marcos legales relevantes. Esto implicaría requerimientos procedimentales como la responsabilidad de Estados acreedores a participar en las negociaciones de reestructuración de la deuda cuando un país prestatario no la puede cubrir, tal como es contenido en el Principios 7 de los Principios sobre Promoción de Otorgamiento y Toma Responsable de Préstamos Soberanos provistos por la Conferencia de las Naciones Unidas sobre Comercio y Desarrollo (UNCTAD por sus siglas en inglés). Además, el ejercicio de la autoridad pública con relación a la reestructuración de la deuda soberana también necesita cumplir con requerimientos relacionados con los derechos humanos. Esto comprende, particularmente, la prohibición de retrocesos discriminatorios o injustificados de los derechos económicos, sociales y culturales. Una vez más, es crucial que se lleve a cabo una evaluación del impacto en los derechos humanos, antes de acordar los programas de ajustes para los países prestatarios, especialmente con relación a las medidas que afecten a los sectores más pobres de la sociedad. 
- ¿Cómo puede contribuir la Comisión Interamericana de Derechos Humanos a identificar, dar forma y ejecutar el marco legal dentro del cual deberían llevarse a cabo las negociaciones y toma de decisiones entre el FMI y los Estados clientes?

-Las obligaciones bajo la Convención Americana sobre Derechos Humanos se aplican a los Estados Parte incluso en crisis de deuda o en contextos de reestructuración de la deuda. La Comisión Interamericana de Derechos Humanos puede ayudar a los Estados a tomar debidamente en cuenta estas obligaciones. A la luz de su mandato transformador dentro del Sistema Interamericano de Derechos Humanos, la Comisión puede incluir aspectos relativos a cuestiones de la deuda soberana dentro de sus actividades de monitoreo de la situación de los derechos humanos de los 35 Estados miembros de la Organización de los Estados Americanos. En este sentido, la Comisión podría aprovechar diversos instrumentos como son los informes anuales y temáticos por país, las audiencias temáticas y los comunicados de prensa. Las visitas que la Comisión realiza a los países y su interacción con actores relevantes de la sociedad civil pueden ser cruciales para tener una mayor comprensión sobre los impactos de los instrumentos financieros en cuestión. En este sentido, parecería crucial mantener y profundizar el diálogo con otras instituciones relevantes como la CEPAL y los órganos relevantes de derechos humanos de Naciones Unidas.

En términos generales, es importante que el FMI tome en consideración el marco regional de derechos humanos a la hora de llevar adelante sus actividades en América Latina. La Corte Interamericana y la Comisión hicieron hincapié en la necesidad de combatir la exclusión social y las desigualdades económicas, lo cual se ve reflejado en las importantes innovaciones jurisprudenciales de la Corte en materia de derechos económicos, sociales, culturales y ambientales. Es de suma importancia que el FMI considere estos derechos a la hora de elaborar sus propuestas de reestructuración de la deuda y diseñar los programas 
de asistencia financiera con sus condicionalidades. Como mencioné antes, una forma adecuada de integrar estas cuestiones a las actividades del FMI podría ser mediante las evaluaciones de impacto en los derechos humanos. Nuestra investigación señala claramente que existen sólidas razones que justifican estas evaluaciones para los programas de asistencia financiera del FMI, pero también para otras actividades a través de las cuales el Fondo ejerce un poder económico y político y, por lo tanto, una autoridad pública internacional. 